
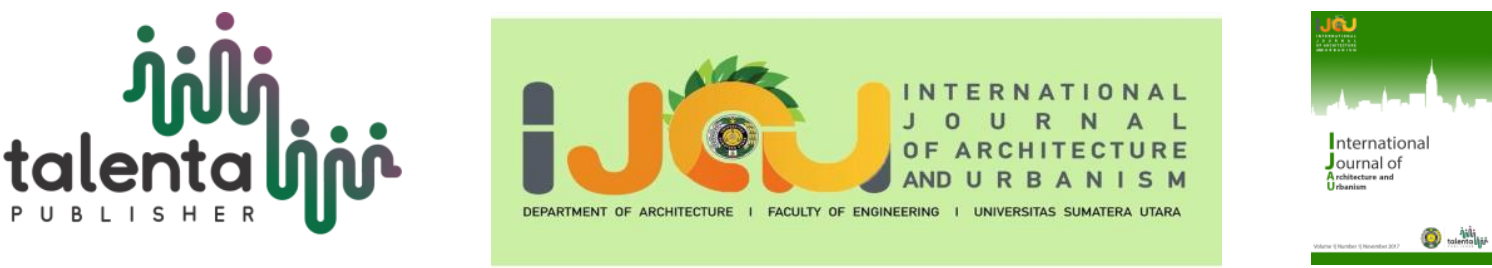

\title{
Revitalization of T-Garden Little Bali in Medan as Education and Recreation Based Tourism Object in Deli Serdang Regency
}

\author{
Yeny Salkina $^{1^{*}}$, Dwi Lindarto Hadinugroho ${ }^{1}$ \\ ${ }^{I}$ Architecture Department, Faculty of Engineering, Universitas Sumatera Utara, Medan, Indonesia
}

\begin{abstract}
The tourist area of Little Bali T-Garden in Medan is located in Jati Kesuma Village, Kec. Namorambe, Deli Serdang Regency, North Sumatra. Which is one of the natural tourist areas located on the edge of Medan City. The place has an area of \pm 20 hectares dominated by green open space. This research focuses on knowledge in utilizing existing potential to have a positive impact. The purpose of this research is to revitalize the tourist area to make it more vibrant and useful. This research was conducted using qualitative methods, namely making direct observations in the research area. The phenomenon that occurs in tourist areas has an irregular arrangement and does not fully utilize the land area. The circumstances that occur are things that considered as potentially not being used. Area revitalization uses Place Attachment theory as a basis, outdoor space design theory as a determinant of the needs of tourist areas, and Kevin Lynch's theory will be used to determine what is considered attractive and has the potential to be developed or removed. These results were obtained from the revitalization of the area as an educational and recreational tourism object in Deli Serdang Regency.
\end{abstract}

Keyword: Kevin Lynch Theory, place Attachment

Received 29 September 2021 | Revised 31 October 2021 | Accepted 31 October 2021

\section{Introduction}

Indonesia is the largest archipelago country in the world, with an area of 1,905,569 km2 and has more than 17,504 islands. The natural beauty of Indonesia has the potential for the development of tourism in Indonesia [1]. With this condition working on ecotourism is one step to increase tourism potential in Indonesia. The natural beauty of Indonesia has the potential for the development of tourism in Indonesia. In this case, working on ecotourism (ecotourism) as a step to increase tourism potential in Indonesia. Rural areas have natural resources in the form of physical, social, and cultural, where these resources can be utilized as ecotourism attractions.

\footnotetext{
*Corresponding author at: Department of Architecture, Faculty of Engineering, University of North Sumatra, Perpustakaan Street, J07 Building, Medan 20155, Indonesia

E-mail address: yenysalkina1@gmail.com
} 
T-Garden Little Bali in Medan is one of the tourist attractions located in the countryside on the edge of the city of Medan, nuanced Balinese style. With an area of 20 hectares. Not all land has the potential to be used properly to attract the attention of visitors. Revitalization program is one of the strategies in tourism development. the revitalization of T-Garden Little Bali in Medan as one of the tourist attractions in Medan City is a form of support for the preservation of attractions and culture.

\section{Literature review}

The revitalization process of an area includes the improvement of economic, physical, urban space, and building aspects. Revitalization on the physical aspect is a short-term strategy to encourage increased economic activity in the long run [2]. Needs to improve public spaces in an area or city, but not in the long term. The benchmark for the success of the revitalization of the area is to create an attractive environment with a positive impact and improve people's lives. The pedestrian space is used for roads, sports, as well as for mass activities such as parades. Apart from that, the outdoor space is also a place to stay where you can sit back, read books, discuss, enjoy the scenery, speeches, music concerts, picnics, and other activities. Whereas vehicle space used to go to a place without obstruction can be straight space, uphill, turning, descending, stopping at traffic lights, entering, leaving, and so on. Besides, outdoor space for vehicles is also used for parking, transporting passengers or dropping passengers, and so on [3].

Ecotourism is a tourism activity that pays attention to the preservation of tourism resources. The development of ecotourism in forest areas that are still virgin and untouched and do not know the saturation of the market can attract the attention of visitors to make it one of the tourist destinations. Therefore in the development of ecotourism must refer to the principles of ecotourism, to achieve success in the use and preservation of nature (Fandeli, 2000) [4]. Space is a territory not only with physical restrictions but tends to be more abstract. Whereas place is a place formed by human relationships with physical arrangements, meanings, and group or individual activities. So place attachments are some concepts that can describe the quality of the relationship between the community and a place [5].

Place identity refers to the symbolic importance of a place as a hiding place to pour out the contents of the heart or emotions and give meaning to relationships and life goals. Place dependence reflects the importance of a place to provide facilities and features that support specific goals or reflect the desired activity (William \& Roggenbuck, 1989) [6]. In general, public space is an open space that supports human needs for places and containers to gather, interact, with other humans in carrying out joint activities [7]. The shape of this public space depends on the pattern of the structure of the building. The basics of forming open space according to Kevin Lynch: Vitality, Fit, Sense, Control, and Access. 
The environment is a combination of physical conditions (water, soil, solar energy, floral and fauna, and minerals with institutional human decisions on how to use the physical environment. There are three main characteristics to meet these criteria: Sustenance, Safety, and Consonance [8], according to Lynch (1981), the sense divided into three things, namely: Place is something that is invisible and has meaning and has a close relationship with culture, the formal structure of one's ability to be oriented to the city setting, events, everything that is influenced by daily activities and culture [9].

Kevin Lynch said that the image of a city is formed from 5 elements of the face of the city, namely path, nodes, district, landmark, and edge [10].

Paths are generally in the form of pedestrians and roads used for the circulation of people and vehicles. The traits of a path are that it has turns, offers appearance, and serves a purpose. A node is a meeting between several road segments that form a separate space and is a strategic area circle where all activities and road segments meet and can convert into activities and other road segments. The characteristics of a node can be an activity centre, a meeting of several road segments as a place to change direction means of transportation and intersections. A district is an area or urban area with a two-dimensional scale that tends to have almost the same characteristics, both in its distinctive patterns, shapes, and boundaries. The community will feel a feeling of starting and ending. Regional characteristics, namely having clear boundaries, having distinctive features, having a similar shape, and having function and position. Landmark is one of the elements that decorate city space, functions as a marker and identity of an area. The characteristics of landmarks are iconic, original, high, easy to see, unique in shape, easy to see, easy to remember, real, and can describe identity area. An edge is a linear element that is not used as a line, located on the boundary of an area that functions as an area boundary such as a coast, topography, railroad tracks, walls, etc. The features of the banks can be rivers, beaches, railroads, and have clear visuals.

\section{Research methods}

The method used in this study is qualitative, to get descriptive data that is unwritten or oral words from visitors and managers directly, as well as observed behavior [11]. This research also uses a descriptive approach by displaying the problem to be examined. To obtain data and information, and a field survey was conducted to get a clear picture of the area to be studied [12].

The research location is in Jati Kesuma Village, Kec. Namorambe, Deli Serdang Regency, North Sumatra. The Little Bali T-Garden area in Medan is located \pm 19 KM from Medan City. Has a land area of \pm 20 hectares, contour topographical conditions [13]. The boundaries of the T- 
Garden area are Little Bali in Medan, in the eastern part bordering the river and River Valley Residence while in the south, west, and north bordered by plantations owned by residents.

Facilities and infrastructure provided at T-Garden Little Bali in Medan are quite complete, such as parking lots, toilets, water games (under construction), flying fox, ATV, Ranch, Resort equipped with fish ponds, huts, cafes, game rides children and a variety of interesting photo spots [14]. In general, the T-Garden area of Little Bali in Medan has contoured and unspoiled land. There are attractive potentials such as oil palm plantations, large green grass fields, and rivers. This potential has not been well developed, so a revitalization of the T-Garden Little Bali in the Medan area is needed so that the entire tourism area is alive and useful.

\section{Research Area Analysis}

The path element in Little Bali in the Medan T-Garden area consists of vehicle lanes and pedestrian paths. The physical condition of the vehicle lane is still in the form of soil and rocks. The pedestrians have physical conditions in some parts that have pavement, and other parts are still original. The node elements in the area are found in the resort. Nodes here is a meeting between the paths and a place of change of direction by visitors in the tourist area. The district element in the area is located in resorts that have clear boundaries and entrances, lawns bordered by pedestrian paths, gardens lined with trees, horse riding areas, rice fields, sugar palm plantations, and water parks. Landmark elements in the area can be used as a place to carry out various activities, such as the resort area, this place is better known and sticks to visitors' memories, in the form of markers such as gates, signboards (directions) at resorts, horse fields, and dominating areas. The edge of the elements in the area is on the river bank. The rivers in this area do not get much attention are not well maintained so that they are not attractive to be used as a view, while on the riverbank there are seats for visitors besides that there are also edges in the form of topography covered with grass.

\section{Results and Discussion}

Revitalization needs to be done to improve the image of an area. Several points in the area that are considered to have good potential will be developed. This area has an area of \pm 20 hectares, which will be used as an outbound tourism object with the theme of education and recreation. Sugar palm plantations and river valley residential housing have the potential to improve the region's economy. In this Aren plantation, agro education activities are carried out by utilizing palm tree resources. The results of these educational activities can be brought home or sold back to cafes and canteens in tourist areas. This activity can be used as a concept to increase the knowledge and economy of the surrounding community in processing oil palm resources [15] (Figure 1). 


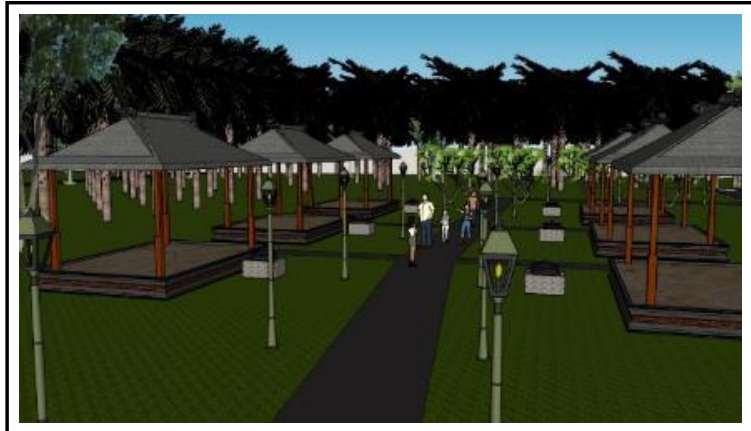

(a)

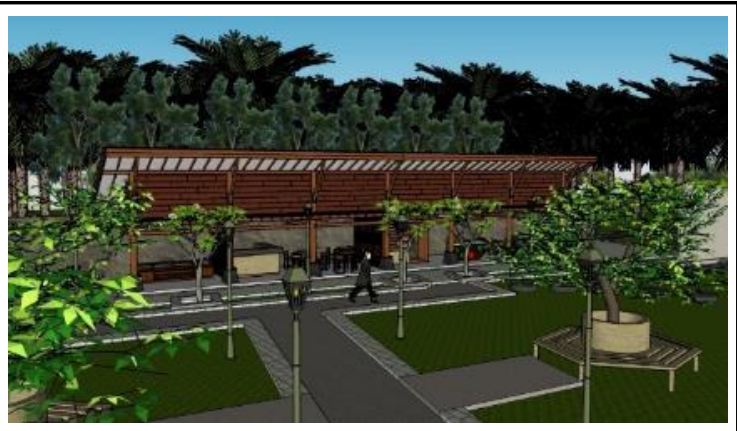

(b)

Figure 1 (a) A place for processing palm sugar and fro, (b) A typical snack bar from the palm tree

River Valley Residence is located in the east of the tourist area. This housing can use as a source of the permanent market in this tourist area by offering a regular payment system every month. This gives visitors freedom from the River Valley Residence housing to relax in this tourist area (Figure 2).

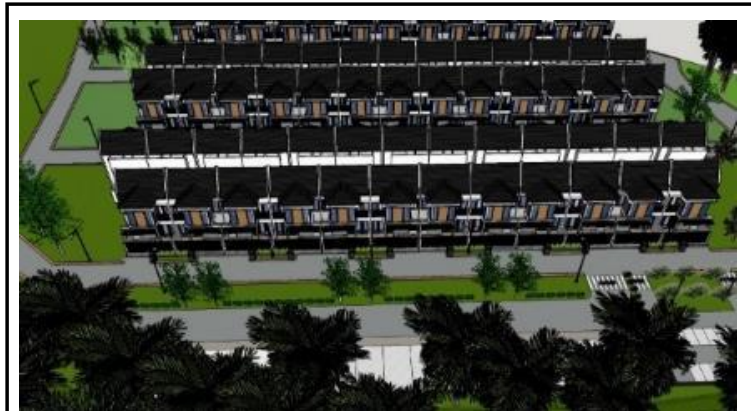

(a)

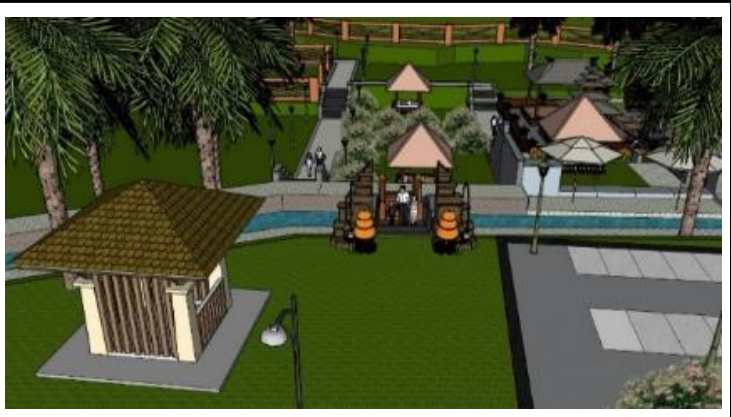

(b)

Figure 2 (a) River Valley Residence, (b) Entrance of the River Valley Residence

There are several gathering points in the tourist area of the T-Garden Little Bali in Medan, namely horse riding fields, sugar palm plantations, Bali resorts, and waterpark, but the activity with the highest daily usage is centered on the Bali resort so it needs to be revitalized in other tourist areas to attract visitors and so This tourist area is becoming more lively. The physical condition of some of the facilities available in the T-Garden tourist area of Little Bali in Medan such as vehicle lanes that have not been designed and are still in the form of potholes so that the structure needs to be improved and provide road directions (Figure 3 and 4).

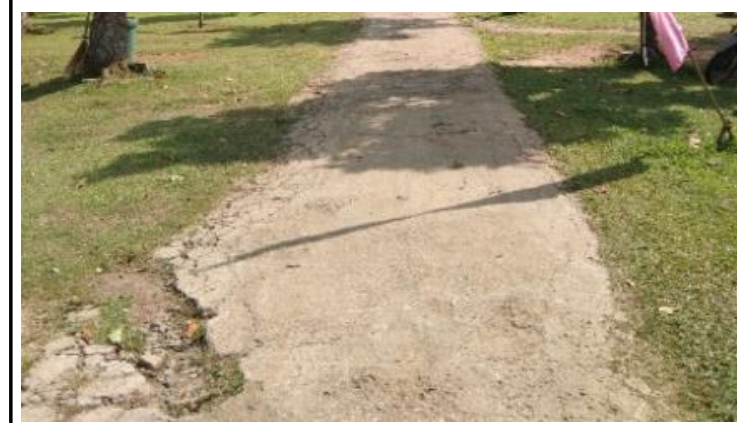

(a)

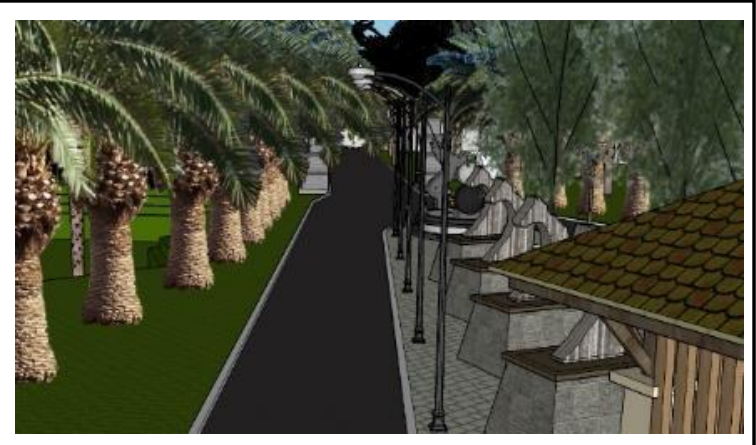

(b)

Figure 3 (a) Vehicle lane before revitalization, (b) Vehicle lane after revitalization 


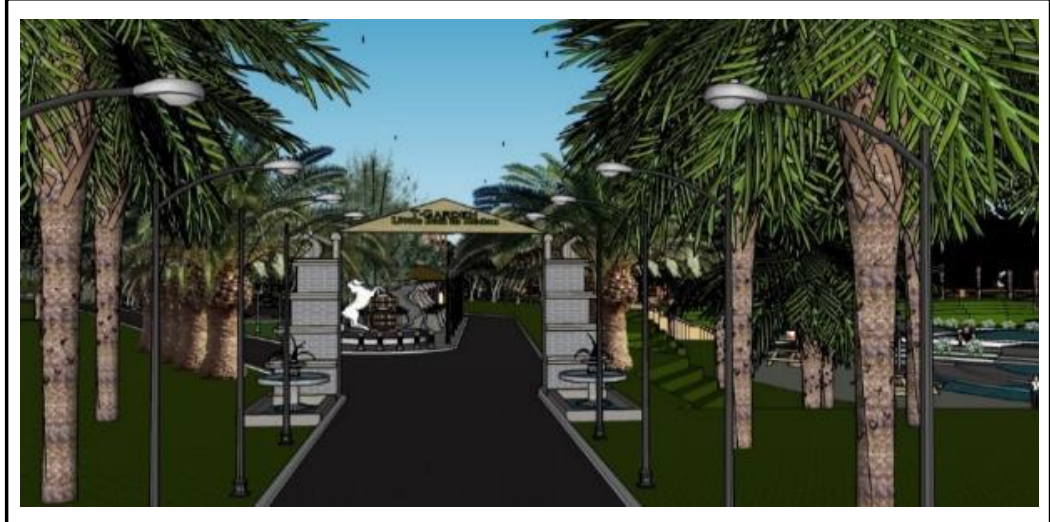

Figure 4 The main gate and sign board in the form of a horse statue

The provision of pedestrians is indispensable in a tourist area; its function is to direct visitors within the tourist area and can also give a neat and orderly impression to the tourist area. Providing resort facilities such as huts, cafes, and park benches needed in a tourist area can be used as a concept to accommodate visitors by creating a more comfortable social area such as a cafe near the parking area, a cottage inside the Bali resort, a cafe in the waterpark area and the pavilion in the palm tree agro education area (Figure 5).

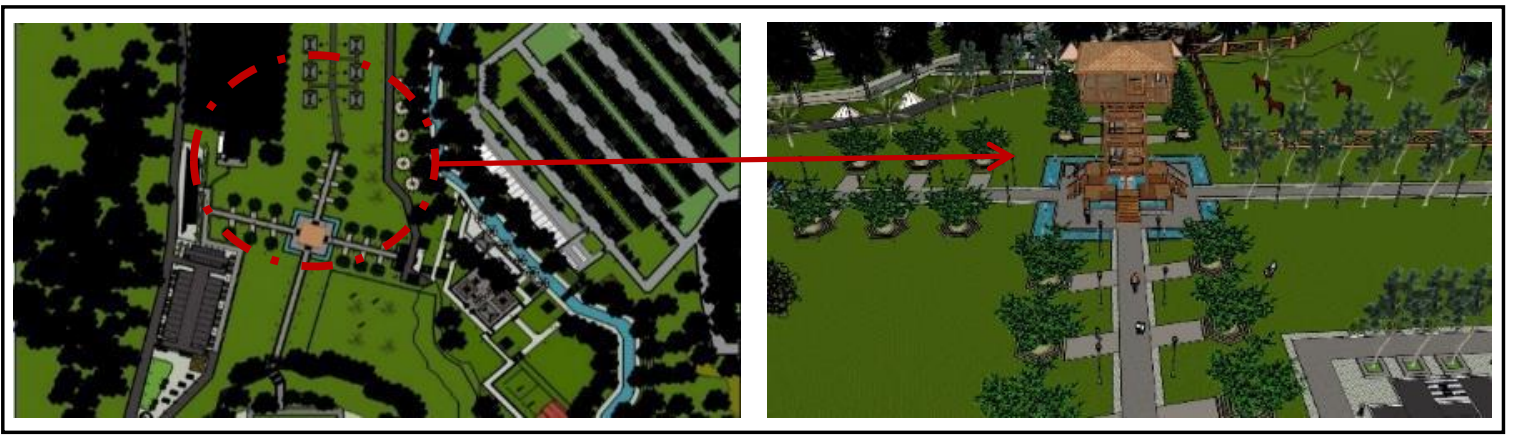

Figure 5 Planned pedestrian path design

Little Bali's T-Garden area in Medan has several tourist area points that are considered potential in tourism development, namely the agro-palm resource processing tourism, Bali-style resort tourism, ranch tourism, river adventure and camping land tourism and provide education in caring for horses and tourism water park. Horse farm that provides horse training services and follows horse care processes such as cleaning and feeding horses. this activity will be guided by professionals (Figure 6).

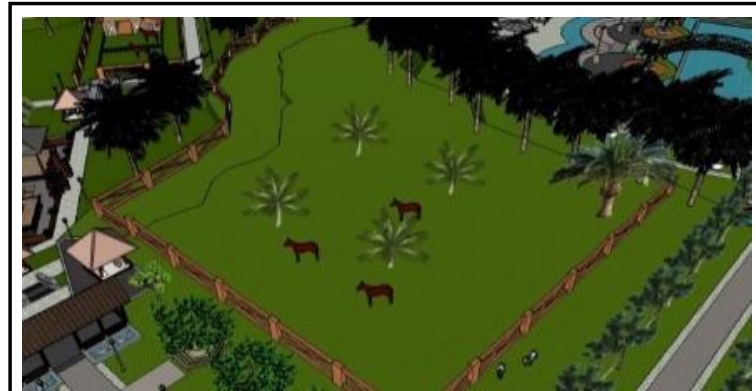

(a)

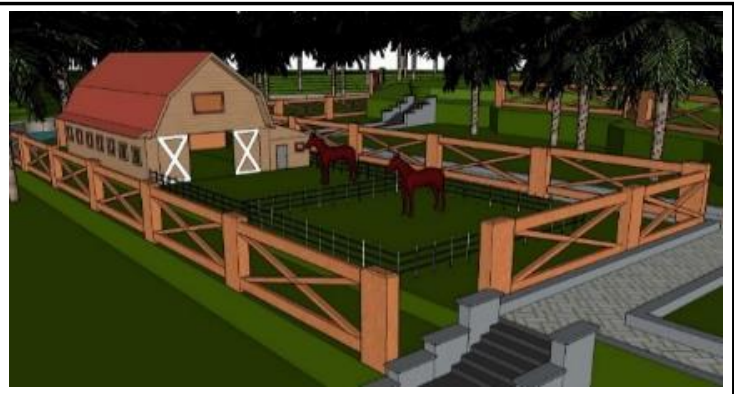

(b)

Figure 6 (a) Ranch area design plan, (b) Horse care area design plan 
This area tends to be quiet due to the absence of any activities there so that the concept of tourism is made by utilizing existing natural resources namely, agro-tourism education in processing palm sugar and fro (Figure 7).

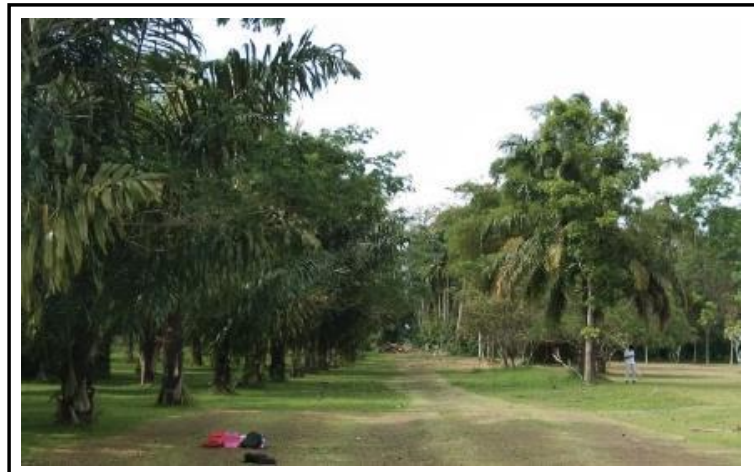

(a)

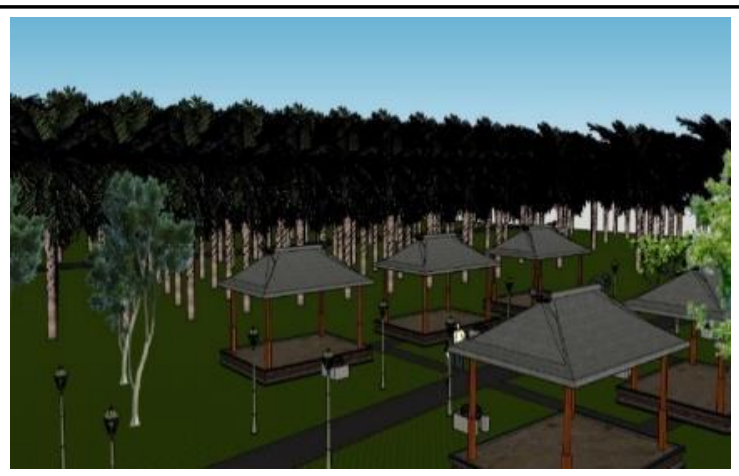

(b)

Figure 7 (a) Palm plantation area, (b) Agro tourism area design plan on the palm plantation

The potential of rivers can be developed by creating a riverside camp, a camping program with a panoramic sensation of rivers and forests combined with outdoor activities such as camping, bonfires, and river adventures (Figure 8).

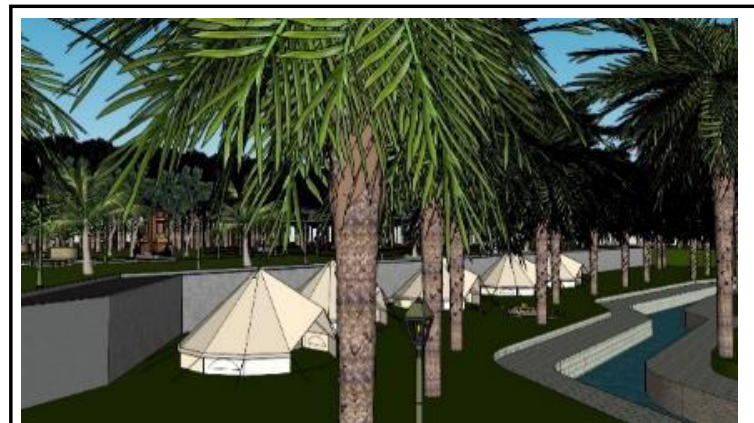

(a)

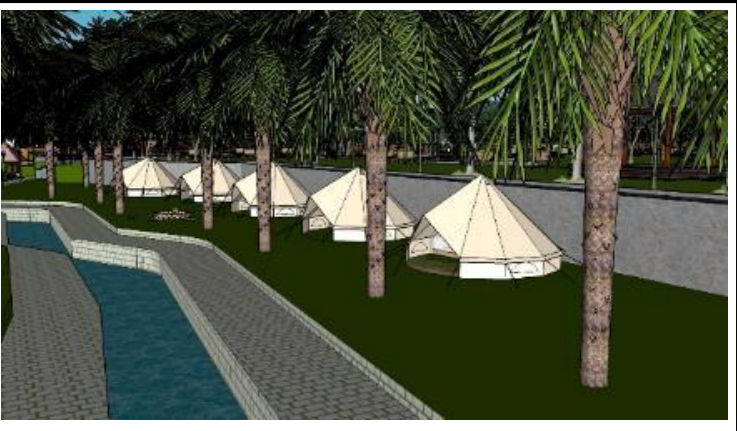

(b)

Figure 8 (a) Riverside camp area design plan, (b) River area

This tourist area also provides a waterpark which is still under construction, so the authors provide a waterpark design plan with the concept of a beach so that it is in harmony with the resort so that it can become a character in this tourist area (Figure 9).

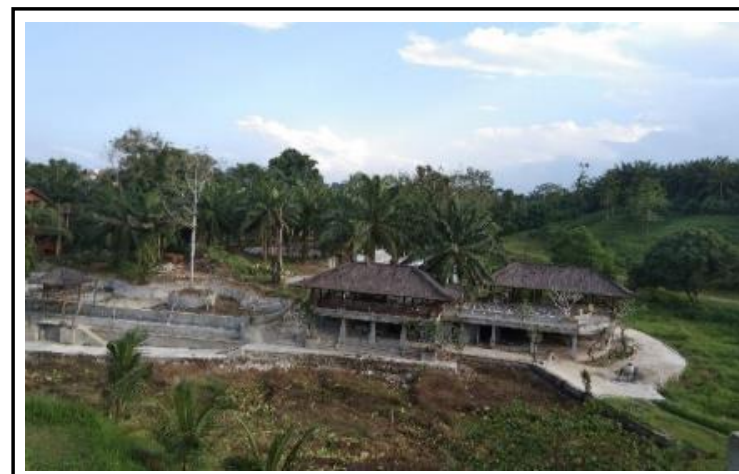

(a)

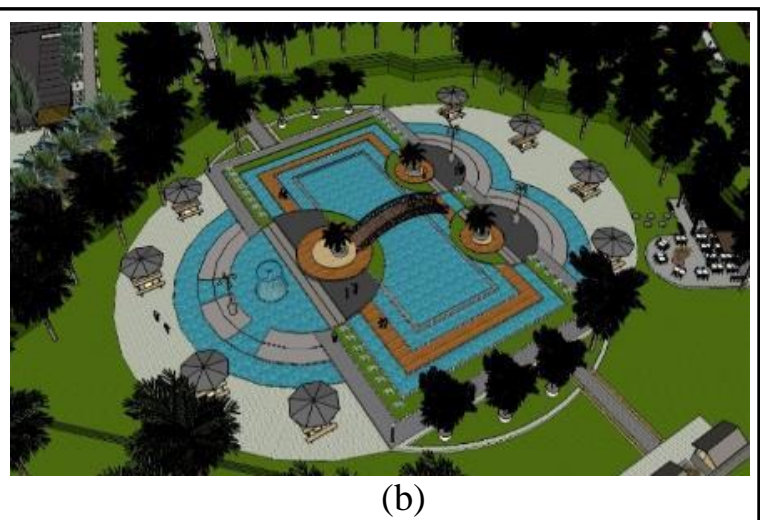

(b)

Figure 9 (a) Waterpark development area, (b) Waterpark area design plan 
The resort area is the most crowded; its strategic location is crossed by a river so that it gives a beach-like atmosphere to visitors and also provides huts, as well as Balinese buildings which are attractive spots in this tourist area (Figure 10).

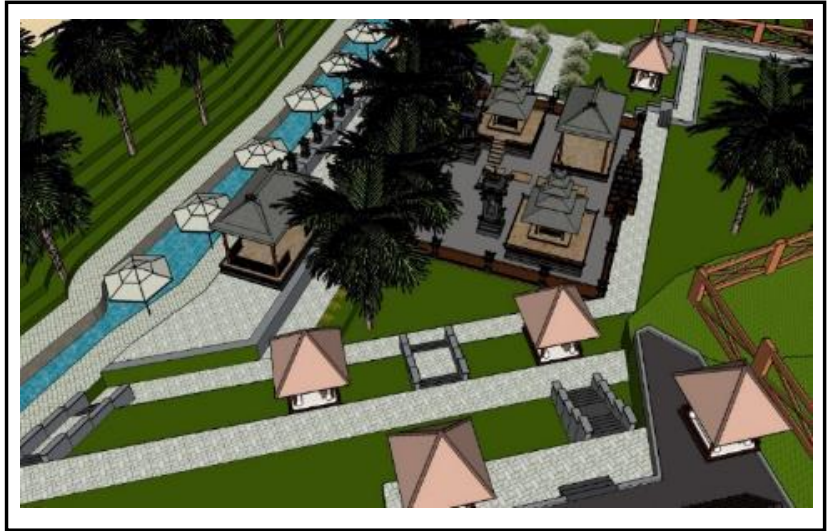

Figure 10 Bali resort area

Edges that distinguish between tourist areas are trees and pedestrians. Revitalization is carried out in processing the boundary form to provide a better and stretcher image of the corridor, such as on the edges of the parking lot and horse riding area (Figure 11).

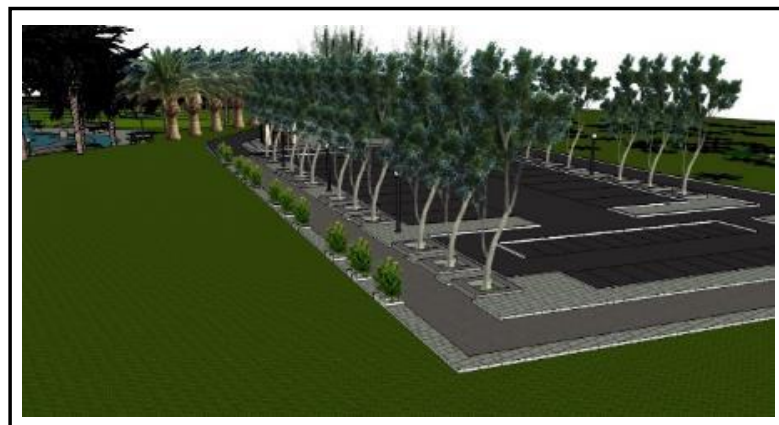

(a)

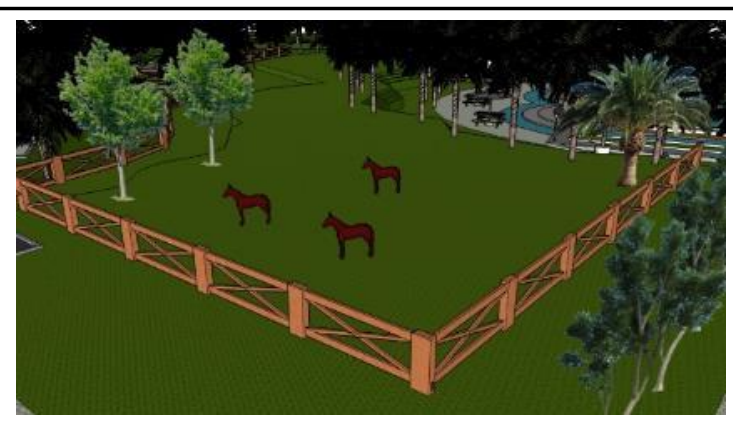

(b)

Figure 11 (a) Edge design plan in the parking lot, (b) Edge design plan in the ranch area

The landmark in the Little Bali in the Medan T-Garden area can be a gate because the gate is a marker gate. As the tallest and most easily seen object, the tower of view can also be a landmark. Based on the crowd and the things that are most remembered by visitors, the Bali resort is suitable to be a landmark (Figure 12 and 13).

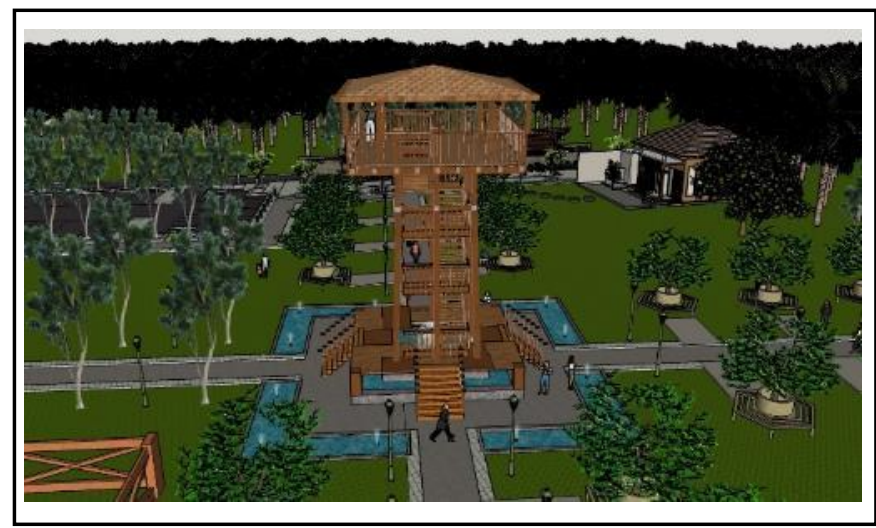

Figure 12 Bali resort area 


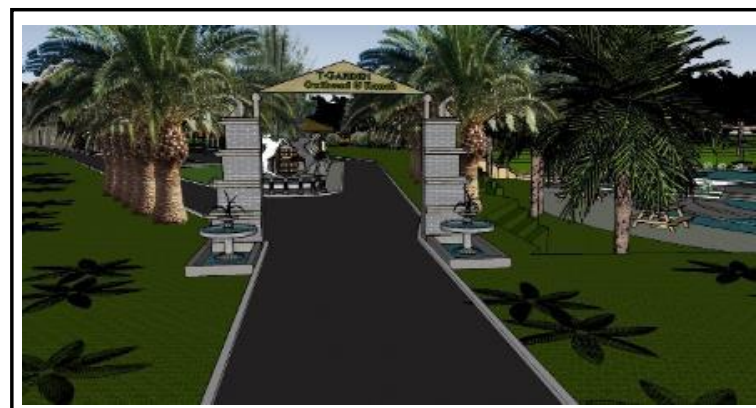

(a)

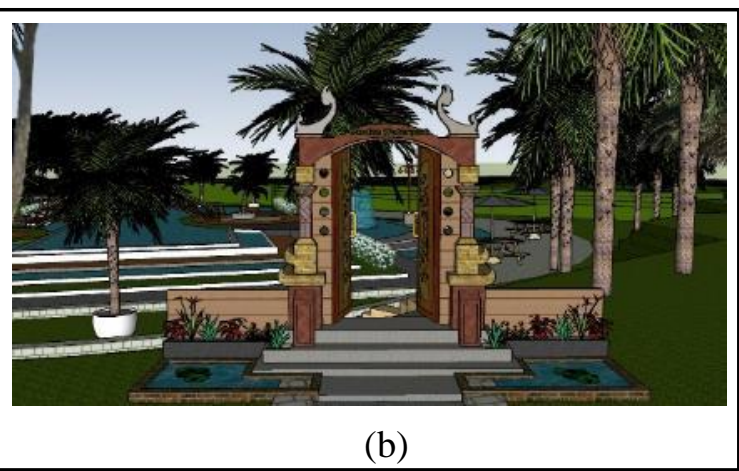

(b)

Figure 13 (a) Main gate design plan, (b) Archway design plan in each tourist area

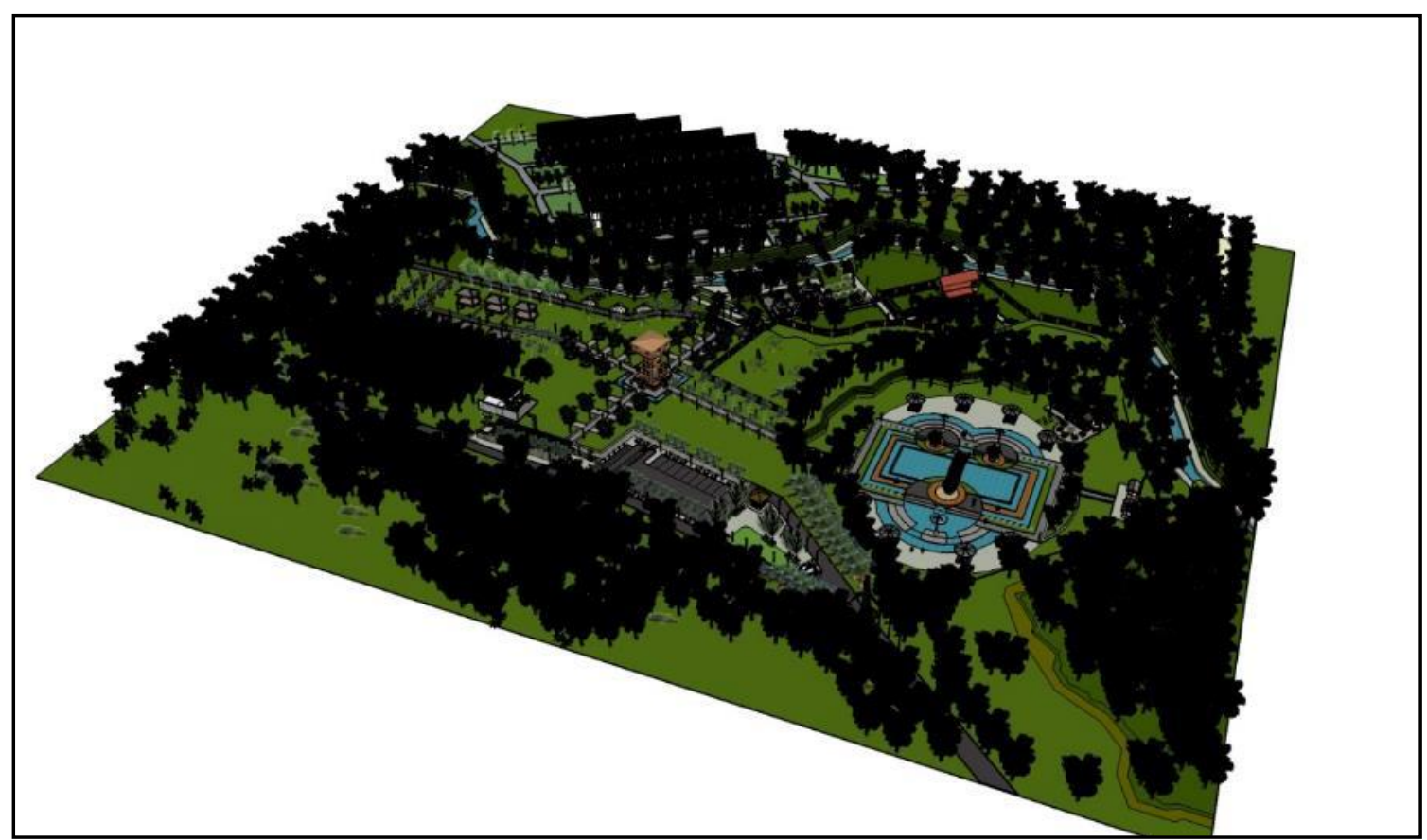

Figure 14 Perspective of tourist areas

\section{Conclusion}

The T-Garden tourist area is located on Jati Kesuma Village, Namorambe District, Deli Serdang Regency, North Sumatra, \pm 19 KM from Medan City, and has a land area of \pm 20 hectares. The design of the revitalization model with the Place Attachment theory approach is to design a comfortable and beautiful tourist area so that visitors feel at home and intend to visit again. In implementing the city image forming elements that need to be considered are the paths, vertices, edges, districts, and landmarks that are applied to this design.

\section{REFERENCE}

[1] E. Geography, "Phenomena of the Outermost Small Islands and Administrative Regions of Indonesia," vol. VI, no. 1, p. 25, 2018.

[2] W. Handoko, "Revitalization of Colonial Fortress Areas in the Maluku Archipelago as Part of Regional Spatial Planning Development," Head of Archeology, vol. VII, no. 13, pp. 10-11, 2011. 
[3] Y. Ashihara, Exterior Design in Architecture, New York: Van Nostrand Reinhold Company, 1970.

4] C. Fandeli, Ecotourism Business, Yogyakarta: Faculty of Forestry UGM [with] Student Library [and] Natural Resources Conservation Unit DIY, 2000.

5] M. M. H. Sesunan, "Evaluation of Place Attachement on Revitalization," E-Journal of Graduate Unpar, vol. I, no. 2, pp. 40-42, 2014.

6] R. William and W. Roggenbuck, Authors, Measuring Place Attachment: Some Preliminary Results. [Performance]. Paper Presented at the Session on Outdoor Planning and Management NRPA Symposium on Leisure Research San Antonio, Texas October 20-22, 1989.

7] S. Darmawan and T. B. Utami, "Utilization Patterns of Open Space in Urban Village Settlements," Journal of Architecture, Building \& Environment, vol. VII, no. 3, p. 128, 2018.

[8] R. Efendi, H. Salsabila and A. Malik, "Understanding of Sustainable Environment," understanding of sustainable environment, vol. XVIII, no. 2, pp. 77-78, 2018.

9] K. Lynch, A Theory Of Good City From, Cambridge: The MIT Press, 1981.

[10] K. Lynch, The Image of the City, Cambridge: The MIT Press, 1960.

[11] Wahidmuri, "Exposure of Qualitative Research Methods," Repository.UIN, Malang, 2017.

[12] T. Soendari, "Descriptive Research Methods," UPI File Directory, [Online]. Available: http://file.upi.edu/Dirirect/FIP/JUR._PEND._LUAR_BIASA/195602141980032TJUTJU_SOENDARI/Power_Point_Perkuliahan/Metode_PPKKh/Pen Research_Descriptif.ppt_[Compatibility_Mode].pdf. [Accessed August 2, 2020].

[13] "PariwisataSumut.Net," 15 June 2019. [Online]. Available: https://www.pariwisatasumut.net/2019/06/t-garden.html. [Accessed August 2, 2020].

[14] B. Erik, Interviewee, What are the activities at T-Garden Little Bali in Medan. [Interview]. March 15, 2020.

[15] S. M. Rusian, Baharrudin and I. Taskirawati, "The Potential and Utilization of Arenga Pinnata with Agroforestry Patterns in Palakka Village, Barru District, Barru Regency," Perennial Journal, vol. XIV, no. 1, pp. 24-25, 2018.

[16] G. Setiati, I. Santosa and A. Syarief, "Gender and Place Attachment at a Coffee Shop in Bandung," Journal of Sociotechnology, vol. XIV, no. 3, p. 302, 2015.

[17] N. Farasa, "The Existence of Dugdheran Tradition: Place-Making and City Senses in Semarang City, Central Java," in Local Wisdom and the Built Environment, Medan, 2017.

[18] C. Fandeli, ecotourism exploitation, Yogyakarta: Faculty of Forestry UGM [with] Student Library [and] DIY Natural Resources Conservation Unit, 2000. 